\title{
dBASE III Plus によるデータベースの作成（2）
}

\section{滝沢隆安*}

前回は, きわめて簡単な「文献情報」データベー スを, dBASE III Plusのアシストメニューだけで作 る方法を紹介した。しかし，あまりにも簡単なデー タベース過ぎるし，アシストメニューだけでは使い 勝手が悪い。今回は, データベースの内容を（筆者 が）まあまあ実用的と思われる程度にし，使い勝手 を良くする第一段階の工夫をしてみよう。

\section{3. 文献カードの作成と文献情報の入出カ}

1) 文献カードの作成

筆者は, 前回述べたように, 四半世紀に亘りパン チカードの文献カードを使っていた。現在でも京大 カード等の文献カードを使っている人も多いだろう。 経験的に考之, 文献整理に必要な書誌的事項は, 困 9 のように，8種類程度で十分と思われる。そこで, 図 9 の文献カードを, CRT のスクリーン上に描くプ ログラムを dBASE III Plusで書いてみよう。

まず,レコードのフィールドを次のように決める ことにする(図10参照)。ただし，フィールドの型式
はすべて文字型とする。

(1)文献番号（整理番号）

ANK 文字 (Alphabet, Nmeric and Kana で, 直 接キ一から打ち込める文字) の一連番号は 5 桁で 十分だろう。名前を SERNUM (Serial Number のつもク)，幅は 5 としよう。

(2)著者名（英名）

すべての著者名を書くと, ANK 文字 100 程度は必 要になる。これを超えるとき，一部を省略するこ とにする。図 9 に納めるには，2フィールドが必 要である。名前をENAME1と ENAME2（English Nameのつもク）とし，幅はそれぞれ50とし よう。

(3)著者名（日本名）

すべての著者名を書くと, 日本字50程度は必要に なる。これを超えるとき，一部を省略することに する。日本字 1 字は ANK 文字 2 字のスペースが 必要である。名前をJNAME1と JNAME2 (Japanese Name のつもり) とし，幅はそれぞ

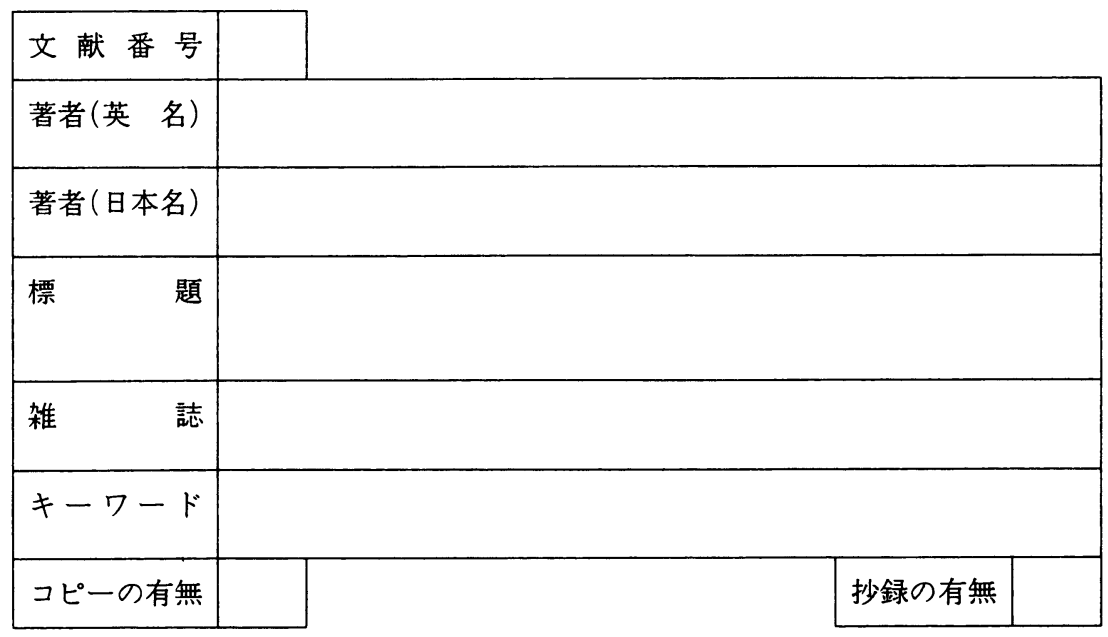

図 9.文献カード 


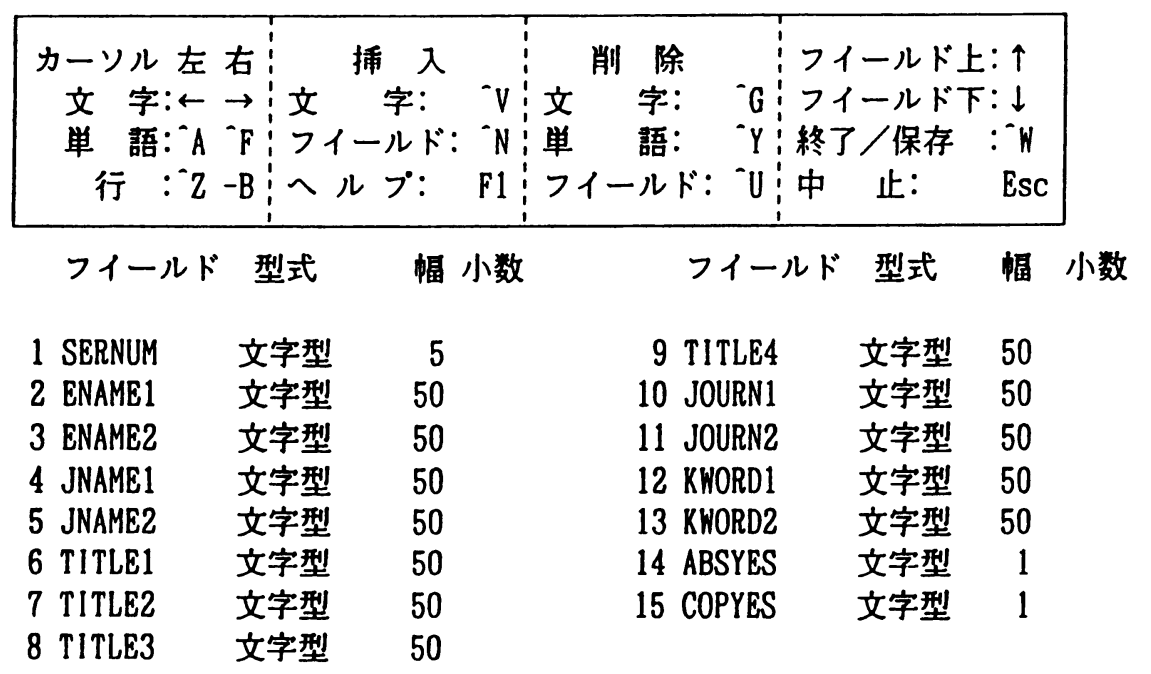

図10.「文献情報」レコードのフィールド作成

れ50としよう。

\section{(4)標題}

単行本の一部のこともあり, ANK 文字200程度が 必要になる。名前をTITLE1, TITLE2, TITLE3，TITLE4とし，幅はすべて 50 とよう。 (5)雑誌名（著書，会議資料等のこともある）

名前を JOURN1と JOURN2 (Journal のつもり) とし，幅はそれぞれ50としょう。

(6)キーワード

文献の整理・検索に重要である。たくさんのキー ワードを採りたいが，あまり欲をかかず，ANK文 字100程度にしておく。名前をKWORD1と KWORD2 (Key Wordのつもク) とし, 幅はそれ ぞれ50としよう。

(7)別刷またはコピーの有無

仕事をするとき，その仕事の有用性を判断する必 要がある。そのためには，2次文献から孫引きし， 重要な文献を収集しなければならない。したがっ て, 原本, 別刷, コピーなどの原文の有無を記録 しておく必要がある。名前を COPYES (Copyな どの有無がyes or noのつもり), 幅を 1 としよ う。

(8)抄録の有無

文献を読むと, 要点や抄録を書く人が多い。人に よっては，詳しい抄録を作ることもある。文献情 報の記録媒体を $2 \mathrm{HD}$ 程度のフロッピーディスク にするとき，抄録を丹念に入力すると，ディスク の容量を圧迫する。また, 入力に要する労力を軽
減するため, イメージスキャナーで原文の一部を イメージ情報として記録したくなる。イメージ情 報は, 意外に大きな容量が必要になる。パソコン では, 特に重要なもの以外, 抄録等をあまり記録 しないほうがよいだろう。名前を ABSYES (Abstractの有無が yes or no のつもり), 幅を 1 としょう。

上記のレコードのデータベースファイルの名前を 仮に "BUNKEN"（自動物に拡張子“.DBF"がつけ られる）とし，これをドライブ Bのディスクに作っ てみよう。あらかじめMS-DOSでフォーマット （システムは転送しない）した空のディスクを，ド ライブBにセットしておく。前回紹介した手順で dBASE III Plusを起動し,アジストメニューの 「2. 作成」を選択する。つづいて「データべー ス」ドライブ「B：」を選択し，「ファイル名を入力 してください」で, "BUNKEN"と入力する。「フィ 一ルドの作成」画面で, 図10のように，(1)〜(8)に従 って入力する。

すぐにデータを入力しないで, アシストメニュー へ戻る。「1. 設定」,「データベース」,ドライブ 「B：」, データベースファイルの "BUNKEN" を 選択し，「インデックス・ファイルを使用しますか？

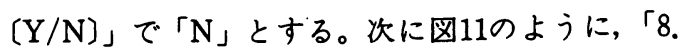
補助」,「ファイル構造表示」を選択する。「プリント しますか?〔Y/N)」で,「N」とすればスクリーン だけに、「Y」とすればスクリーンとプリンターの而 方に図12が出力される。 


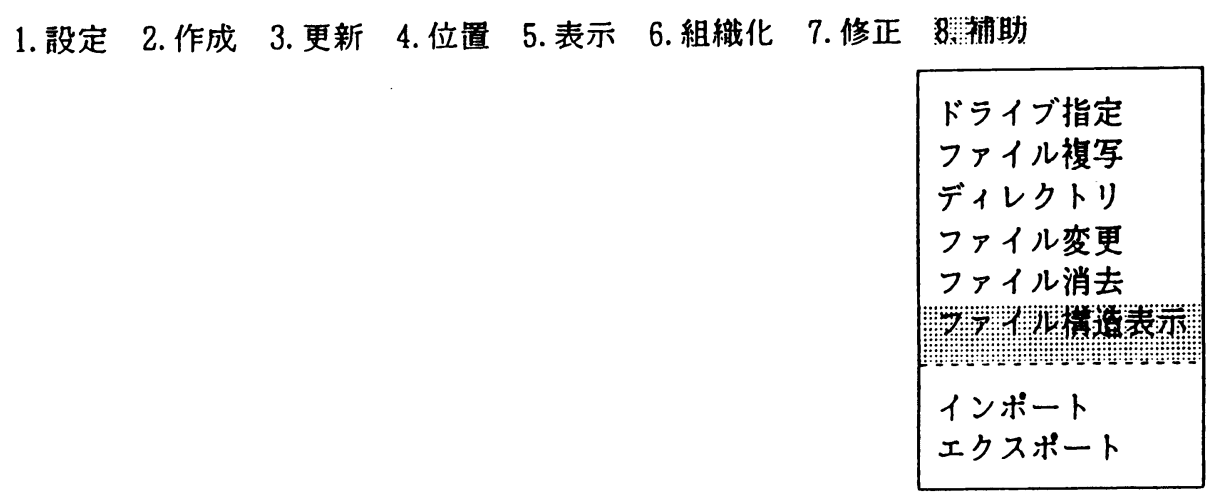

図11.「BUNKEN.DBF」ファイルの構造の確認

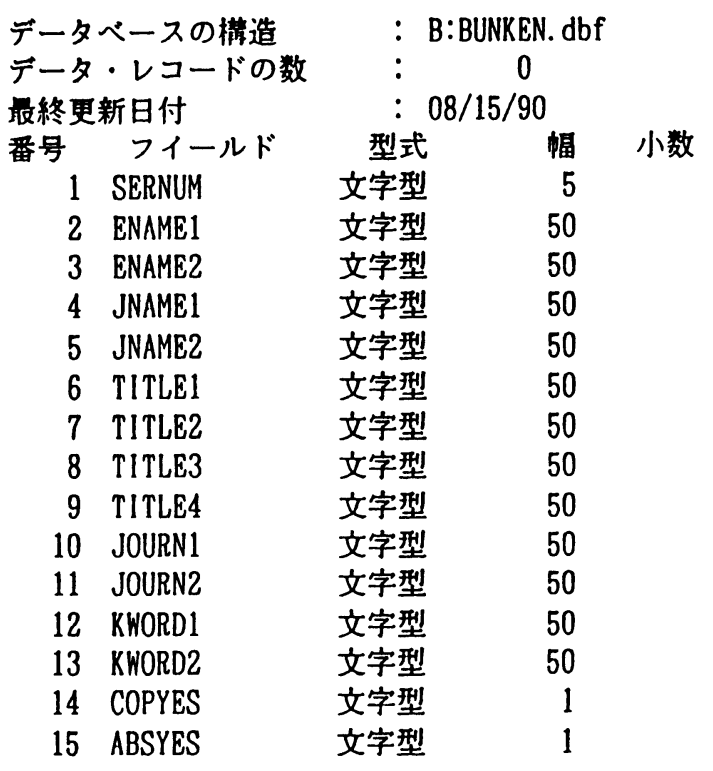

図12.「BUNKEN.DBF」ファイルの構造

以上で，Uとまず準備が終ったので，図 9 の文献 カードをスクリーンに描くプログラムを書くことに しょう。

困9のような四をスクリーンに描く方法として, アシストメニューを使い, スクリーン・フォーマッ ト・ファイルというものを簡単に作る方法がある。 しかし，この方法には画面上でいろいろな制約があ ク，あまり木目の細かいことができない。そこで， プログラムで図 9 を描くことにする。
dBASE III Plus のソフトには, Editor が内蔵され ている。プログラムを作るとき，"MODIFY COMMAND" +プログラム名とすると, 内蔵 Editor 利 用してプログラムを入力できる。しかしこの Editor では，あまり長いプログラムを書くことができない し, 日本字の入力も少々面倒である。筆者は, “CONFIG. DB" というファイルで指定することにより， "MODIFY COMMAND" +プログラム名で, 外部 Editorとして "MIFES"を使うことにしている。プ ログラムを作るとき，使いなれた Editor を利用する ことをおすすめする。ただし，プログラムの大部分 が英字のため,「一太郎」な゙のの日本語ワープロソフ トでは不便である。

リスト1が，図 9 をスクリーン上に描くプログラ ム “CARD”である。ただし，各行の 1 27は行番 号で, 行番号をつけておくと, プログラムを作りや すい。しかし BASIC と違い, dBASE III Plusでは, プログラムに行番号をつけるとエラーになる。した がって, "MODIFY COMMAND" 命令でプログラ ムを作るとき，行番号を省略してて入力する。リスト 1の説明をしよう。

行 1〜 4: コメント行である。文頭の第一文字が "*”の文は,すべてコメント行になる。

行 5 ：スクリーンをクリアする命令。

行 6： "SET COLOR TO" は, スクリーン上に書 〈文字や線の色指定の命令である。色は，B が青， $\mathrm{R}$ が赤, $\mathrm{BR}$ が紫, $\mathrm{G}$ が緑, $\mathrm{BG}$ が水色, $\mathrm{RG}$ が黄 色, W が白である。各色の後に "I" をつけると， 色が反転する。また, “SET COLOR TO" の後ろ 
リスト1。スクリーン用文献カード 作成ブログラム "CARD"

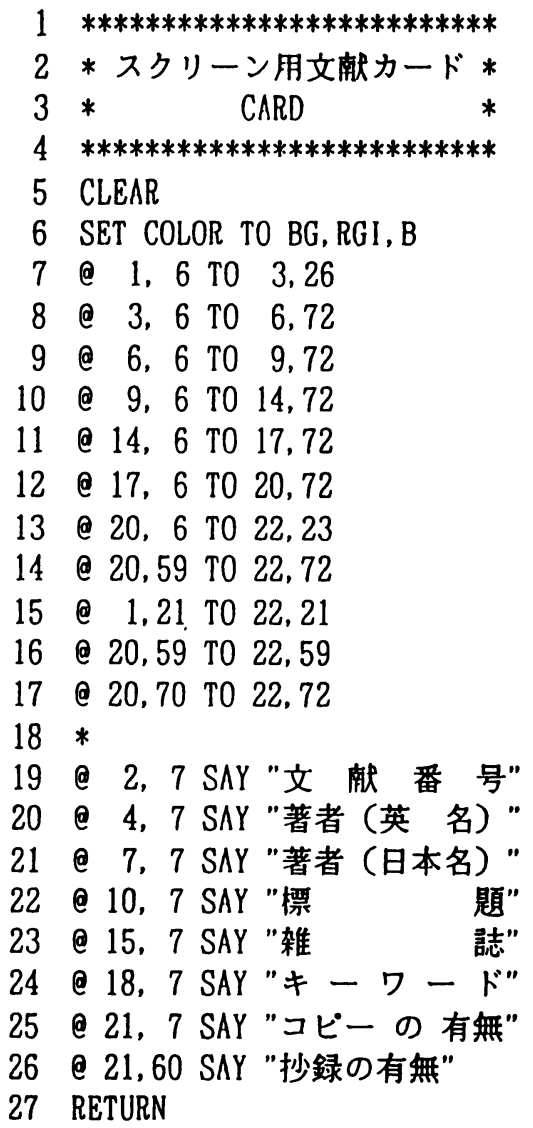

に 3 種類の色指定ができ，1番目がスクリーンに 出力する文字の色， 2 番目が入力する文字の色,

3 番目が線の色である。3 種類の色指定は ", "で つなぐ。"SET COLOR TO"だけだと出力文字の 色を "W" に指定したことになる。行 6 は，出力 文字を水色，入力文字は黄色の反転（黄色の地に 入力した文字が黒で書かれる)，線は青としてあ る。

行 7 ～17：線を引く命令である。各行の先頭の“@” (at マーク) は，テキスト画面（dBASE III Plus はグラフィック画面を使用できない）の座標指定 の命令である。テキスト画面の座標は，横座標を $\mathrm{X}$, 縦座標を $\mathrm{Y}$ とすると, BASIC と同様に, $0 \leqq$ $\mathrm{X} \leqq 79 ， 0 \leqq \mathrm{Y} \leqq 24$ の整数である。ただし， $\mathrm{Y}=0$ 及び $\mathrm{Y}=24$ の行は, dBASE III Plus のシステムで 使うようにしてあるため、できるだけ使わないほ
うが無難である。

BASIC で座標指定するには "LOCATE X, Y" と するが， dBASE III Plusでは “@Y, X" とする。 $\mathrm{X}$ と $\mathrm{Y}$ の順序が逆になっている。行 7 の文は, “テ キスト画面の座標 $(1,6)$ と $(3,26)$ の 2 点 で決められる長方形を, 行 6 で指定した色 B で描 け」という命令である。ただし，行15と行16は， 2 点のX の值が同じである。この場合, 縦に直線 を引く。また，Yの值が同じ 2 点を指定すると， 横の直線を引く。しかし, 図 9 のような図を直線 だけで描こうとすると，縦の直線には問題がない が, 横の直線の両端がはみ出してしまう。「一太郎」 で䄄線を引くとき，はみ出ないようにしてくれる が, dBASE III Plusはそのようにしてくれない。 行18：コメント行である。プログラムリストを見や すくするため挿入してある。

行19〜26："@Y，X"で指定した座標から，"SAY" に続く “.......”" という文字をスクリーンに出力さ せる命令である。

行27：BASIC と同じ機能の命令で，BASICではサ ブルーチンだけで使用するのに対し, dBASE III Plus では Main programで使用してもよい。 リスト1のプログラム“CARD”（自動的に拡張子 ".PRG"つけられる)を走らせてみよう。dBASE III Plus を起動し, “"（ドット・プロンプト）が 表示されている状態で、"DO CARD" +口とする と，スクリーンに図 9 が表示される。

\section{2) 文献情報の入力}

前節で作った文献カードを利用し，文献情報を入 カするプログラム "INPDAT"を作ってみよう。リ スト 2 がそれである。各行の意味は次の通りである。 行 $1 \sim 4:$ :コメント行。

行 $5 \sim 6:$ : の命令を出しておかないと, 入出力に 伴って dBASE III Plusはうるさく反応する。プロ グラムを作るとき，必要な手続きと思ってほしい。 行 7 : コメント行。

行 8 ：「ドライブBにセットしたディスクのデータ ベース "BUNKEN.DBF"を使う」という意味で ある。拡張子は省略する。

行 9 ：RECCOUNT()は, 現在使用しているデータ

ベースに記録されているレコード数を求める関数 である。最初は，ゼロになっている。この值を， NUM という変数に入れる。 行10：リスト1の文献カード作成用プログラムを， 


\section{リスト2．文献情報の入カプログラム "INPDAT"}

\begin{tabular}{|c|c|}
\hline 1 & $* * * * * * * * * * * * * * * * * * * *$ \\
\hline 2 & ＊文献情報の入力 * \\
\hline 3 & INPDAT \\
\hline 4 & $* * * * * * * * * * * * * * * * * * *$ \\
\hline 5 & SET ECHO OFF \\
\hline 6 & SET TALK OFF \\
\hline 7 & $*$ \\
\hline 8 & USE B:BUNKEN \\
\hline 9 & NUM=RECCOUNT () \\
\hline 10 & DO CARD \\
\hline 11 & $*$ \\
\hline 12 & T_SERNUM $=\operatorname{STR}(N U M+1,5)$ \\
\hline 13 & T_ENAMEl=SPACE $(50)$ \\
\hline 14 & T_ENAME2=SPACE (50) \\
\hline 15 & T_JNAME $1=S P A C E(50)$ \\
\hline 16 & T_JNAME2 $=$ SPACE $(50)$ \\
\hline 17 & T_TITLE1=SPACE (50) \\
\hline 18 & T_TITLE2=SPACE (50) \\
\hline 19 & T_TITLE3=SPACE (50) \\
\hline 20 & T_TITLE4 $=$ SPACE (50) \\
\hline 21 & T_JOURN1=SPACE (50) \\
\hline 22 & T_JOURN2=SPACE (50) \\
\hline 23 & T_KWORD1=SPACE (50) \\
\hline 24 & T_KWORD2=SPACE (50) \\
\hline 25 & T_COPYES=" " \\
\hline 26 & T_ABSYES=" " \\
\hline 27 & $*$ \\
\hline 28 & @ 2,22 SAY T_SERNUM \\
\hline 29 & @ 4,22 GET T_ENAME1 \\
\hline 30 & @ 5,22 GET T_ENAME2 \\
\hline 31 & @ 7,22 GET T_JNAME1 \\
\hline 32 & @ 8,22 GET T_JNAME2 \\
\hline
\end{tabular}

BASICのサブルーチンのようにして使う命令で ある。この命令でリスト 1 を実行し，リスト 1 の 最後の RETURN 命令で戻ってきて, 次の行11を 実行する。

行11：コメント行。

行12: STR (A, B) は, BASIC の STR \$関数と似 た命令で, 数值 $\mathrm{A}$ を B 桁の整数の文字に変換す る。したがって行12は,「すでに記録されているレ コード数に 1 を加え，これを 5 桁の整数の文字型 変数に変換し，T_SERNUM に入れよ」というこ とになる。
33 @ 10,22 GET T_TITLE1

$34 @ 11,22$ GET T_TITLE2

35 @ 12,22 GET T_TITLE3

36 @ 13,22 GET T_TITLE4

37 @ 15,22 GET T_JOURN1

38 @ 16,22 GET T_JOURN2

39 e 18,22 GET T_KWORD1

40 @ 19,22 GET T_KWORD2

41 @ 21,22 GET T_COPYES

42 @ 21,71 GET T_ABSYES

43 READ

44 CLEAR GETS

$45 *$

46 APPEND BLANK

47 REPLACE SERNUM WITH T_SERNUM

48 REPLACE ENAME1 WITH T_ENAME1

49 REPLACE ENAME2 WITH T_ENAME2

50 REPLACE JNAME1 WITH T_JNAME1

51 REPLACE JNAME2 WITH T_JNAME2

52 REPLACE TITLE1 WITH T_TITLE1

53 REPLACE TITLE2 WITH T_TITLE2

54 REPLACE TITLE3 WITH T_TITLE3

55 REPLACE TITLE4 WITH T_TITLE4

56 REPLACE JOURN1 WITH T_JOURN1

57 REPLACE JOURN2 WITH T_JOURN2

58 REPLACE KWORD1 WITH T_KWORD1

59 REPLACE KWORD2 WITH T_KWORD2

60 REPLACE COPYES WITH T_COPYES

61 REPLACE ABSYES WITH T_ABSYES

$62 *$

63 USE

64 RETURN

行13〜24: SPACE (n) は「n個のスペース」という 意味で, これをそれぞれ左辺の変数に入れる。 dBASE III Plus では，このようにして文字型変数 の長さを定義しておかねばならない。面倒だが, FORTRAN とCOBOLのような違いが, BASIC と dBASE III Plusの間にある。 行25２6：スペース 1 個を左辺に代入する。“"の 代わりにSPACE（1）としても同じ。 行28：T_SERNUMは，すでに確定している。 "SAY" で所定の位置に出力する。 行29 42: "GET"は, 入力要求命令である。"SAY" 
と "GET" の関係は, BASICの "PRINT" と "INPUT" の関係と同じ。なお, "GET" 命令に より,リスト1の行 6 で指定した入力文字の色 RGI (黄色の反転)に従い, 行13〜26で定義したス ペースの長さだけ所定の位置から黄色で珡りつぶ し, 入力待ちする。

行43："GET" 命令は, "READ" 命令で確定する。 したがって，"READ”命令が実行されるまで，矢 印キーでカーソルを動かし，行29４2で入力した 文字を変更できる。"READ" 命令で実行される と, 先へ進んでしまうため, 入力文字の変更がで きなくなる。

行44：“GET"と "READ"を実行したら，必ず行 うべき手続き，と覚えておくとよい。メモリー節 約のひとつの方法である。

行46：「新しく 1レコード分の容量をデータベース に確保しなさい」という命令。これを実行しない と、すでに記録されていたレコードが書き換えら れてしまう。

行47〜61： "REPLACE A WITH B" は, 「A とい

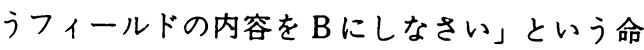
令。面倒だが, "GET"と "READ"だけでは, フ イールドの内容を書き込めない。

行63：「現在使っているデータベースファイルの使 用をやめなさい」という命令。

"DO INPDAT"+口とし, ひとつの文献情報を入
カした例が，図13である。図中の「網掛け」した部 分は, 黄色に塗りつふした地に，黒で文字が書かれ ている。

\section{3）文献情報の出力}

データベース "BUNKEN"に記録した文献情報 を，スクリーンに出力してみよう。プログラムは, リスト3の "OUTDAT" である。

行 8 : 行32で使う変数 RETKEY を, 長さ 1 の文字 型変数に定義しておく。

行10：データベース "BUNKEN"の最初のレコード へポインター（現在入出力の对象としているレコ 一ド番号を指し示す) を移す命令。

行11：行36と对になっている。EOF()は，ポイン夕 一の位置がデータベースのレコードの終わりにな ると「真」，終わりがなければ「偽」であることを 示す関数。"NOT.EOF()" は，その逆。"DO WHILE A….ENDDO"は，A が真」の間， "……" を実行する。BASICの "WHILE A …… WEND"と同じ。したがって行11全体は,「レコー ドがなくなるまで, 行12３5の命令を繰り返し実 行せよ」という命令。

行12：テキスト画面をクリア。

行 13 : 文献カードを出力。

行14：出力文字を水色にする。

行15 29: 所定の位置に各フィールドの内容を書く。 行30：出力文字を黄色にする。

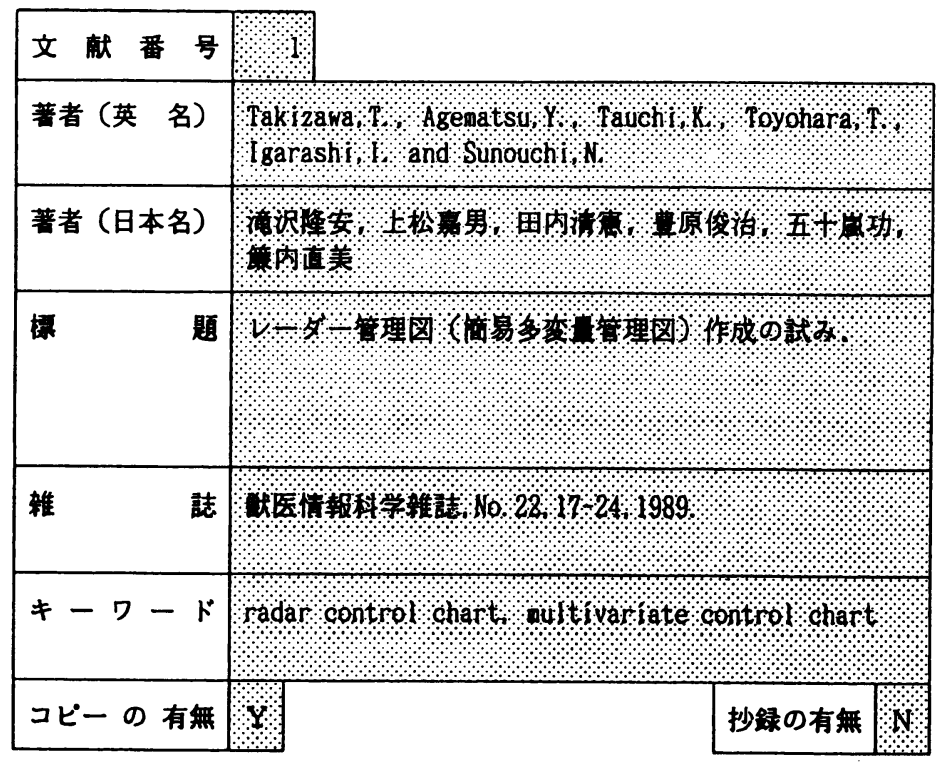

図13．文献カード入力例 
リスト3.文献情報の出力"OUTDAT"

\section{$* * * * * * * * * * * * * * * * * *$ \\ * 文献情報の出力* \\ * OUTDAT * \\ $* * * * * * * * * * * * * * * * * * *$}

SET ECHO OFF

SET TALK OFF

*

RETKEY=" "

9 USE B:BUNKEN

10 GOTO TOP

11 DO WHILE . NOT. EOF ()

12 CLEAR

13 DO CARD

14 SET COLOR TO BG

15 @ 2,22 SAY SERNUM

16 @ 4,22 SAY ENAME1

17 @ 5,22 SAY ENAME2

18 @ 7,22 SAY JNAME1

$19 @ 8,22$ SAY JNAME2

20 @ 10,22 SAY TITLE1
21

22

23

24

25

26

27

28

29

30

31

32

33

34

35

36

37

38

39
@ 11,22 SAY TITLE2

@ 12,22 SAY TITLE3

(e) 13,22 SAY TITLE4

e 15,22 SAY JOURN1

@ 16,22 SAY JOURN2

e 18,22 SAY KWORD1

e 19,22 SAY KWORD2

(2) 21,22 SAY COPYES

e 21,71 SAY ABSYES

SET COLOR TO RG

@ 21,28 SAY"リターンキーを押してください”

@ 21,56 GET RETKEY

READ

CLEAR GETS

SKIP

ENDDO

USE

CLEAR

RETURN
行31〜34：リターンキーを押すまで，画面の表示を 変更しないでおく（実際にはどのキーでもかまわ ない)。このようにしておかないと, 文献カードの 内容が次々に変化してしまう。

行35：ポインターの位置を, 次のレコード番号に進 める。これを省略すると, ポインターが動かない ため, 同じ文献情報だけが何回でも表示され, 行 11〜36が無限ループになってしまう。

"DO OUTDAT" + に記録されている文献情報を, 最初から最後まで, 順に表示する。

以上で，文献情報の入出力が可能になった。しか し，このままでは検索が不能である。次回は，検索 を容易にするため, インデックス・ファイルを作る プログラムを紹介する予定である。

〔追記〕本雑誌の発行回数が年 2 回のため,「文献整 理用プログラム」の主な部分を紹介するだけでも，
かなりの年数が必要になる。修正したい部分がまだ たくさん残されたままのプログラムだが, 現在, 筆 者及び同じ勤務先の研究員が文献整理に利用してい る。未完成のままのプログラムで良ければ，次の条 件で，希望する人にコピーを差し上げます。

1) MS-DOSのシステンディスク (Version3.0以 上)と dBASE III Plus のソフトを持っている 人。

2) MS-DOS でフォーマットした2HDのフロッ ピーディスク1枚（折れないようにケースに 入れたもの), 及び本人宛の宛先を書き, 必要 な金額の切手を貼った返送用の封筒を同封し てくれる人。

3 ) 宛先

干300-01 茨城県新治郡出島村染谷 1,103 財団法人 動物繁殖研究所 滝沢隆安 